\title{
E-cigarette use and smoking reduction or cessation in the 2010/2011 TUS-CPS longitudinal cohort
}

Yuyan Shi ${ }^{1,2}$, John P. Pierce ${ }^{1,2}$, Martha White ${ }^{2}$, Maya Vijayaraghavann ${ }^{3}$, Wilson Compton ${ }^{4}$, Kevin Conway $^{4}$, Anne M. Hartman ${ }^{5}$ and Karen Messer ${ }^{1,2^{*}}$

\begin{abstract}
Background: Electronic cigarettes (e-cigarettes) are heavily marketed and widely perceived as helpful for quitting or reducing smoking intensity. We test whether ever-use of e-cigarettes among early adopters was associated with: 1) increased cigarette smoking cessation; and 2) reduced cigarette consumption.

Methods: A representative cohort of U.S. smokers $(N=2454)$ from the 2010 Tobacco Use Supplement to the Current Population Survey (TUS-CPS) was re-interviewed 1 year later. Outcomes were smoking cessation for 30+ days and change in cigarette consumption at follow-up. E-cigarettes use was categorized as for cessation purposes or for another reason. Multivariate regression was used to adjust for demographics and baseline cigarette dependence level.

Results: In 2011, an estimated $12 \%$ of adult U.S. smokers had ever used e-cigarettes, and $41 \%$ of these reported use to help quit smoking. Smokers who had used e-cigarettes for cessation were less likely to be quit for $30+$ days at follow-up, compared to never-users who tried to quit ( $11.1 \%$ vs $21.6 \%$; ORadj $=0.44,95 \% \mathrm{Cl}=0.2-0.8$ ). Among heavier smokers at baseline (15+ cigarettes per day (CPD)), ever-use of e-cigarettes was not associated with change in smoking consumption. Lighter smokers ( $<15$ CPD) who had ever used e-cigarettes for quitting had stable consumption, while increased consumption was observed among all other lighter smokers, although this difference was not statistically significant.
\end{abstract}

Conclusions: Among early adopters, ever-use of first generation e-cigarettes to aid quitting cigarette smoking was not associated with improved cessation or with reduced consumption, even among heavier smokers.

Keywords: Electronic cigarettes, Smoking cessation, Smoking reduction

\section{Background}

E-cigarettes have been intensively marketed since 2010 resulting in widespread awareness [1-5] and a fifteenfold increase in sales between 2010 and 2014 [6, 7]. However, there is still little population-level evidence describing the association of cigarette smoking behaviors with e-cigarette use [8], and the role of e-cigarettes in tobacco control remains controversial $[9,10]$. Given that few smokers quit successfully in any given year [11], it

\footnotetext{
* Correspondence: kmesser@ucsd.edu

${ }^{1}$ Cancer Prevention and Control Program, Moores UC San Diego Cancer Center, 3855 Health Sciences Drive \#0901, La Jolla, CA 92093-0901, USA ${ }^{2}$ Department of Family Medicine and Public Health, University of California, San Diego, 9500 Gilman Drive \#0628, La Jolla, CA 92093-0628, USA Full list of author information is available at the end of the article
}

has been hypothesized that e-cigarette use may lead to reduced health risks, particularly for heavier smokers, by helping them to either quit cigarettes completely or to substantially reduce the number of cigarettes smoked each day [12]. This is counterbalanced with concern that widespread promotion of e-cigarettes may re-normalize smoking behavior and potentially increase tobacco use among youth [13-16]. The public health arguments against promoting e-cigarette use include that the health effects of long-term use are currently unknown [17], that e-cigarette aerosol contains similar numbers of fine particles, including nanoparticles, as cigarettes [13], and that aerosol may contain numerous toxicants including carcinogenic formaldehyde $[13,17,18]$. 
To date there is limited empirical evidence regarding the effect of e-cigarette use on cigarette smoking behavior, including smoking cessation [13]. A systematic review and meta-analysis by Kalkhoran and Glantz [8] summarized 20 studies and concluded that cigarette smokers who used e-cigarettes were $28 \%$ less likely to quit smoking compared to those who did not use e-cigarettes. Among these 20 studies, 15 were cohort studies with follow-up. Only one published study used a national probability sample of the US: Grana et al. [19] reported that cigarette smokers in 2011 who used e-cigarettes were not more likely to quit or reduce cigarette consumption by the 1-year follow-up time-point.

In this paper we report findings from a longitudinal subsample of the large nationally representative 20102011 Tobacco Use Supplement to the Current Population Survey (TUS-CPS), fielded during a time of rapid uptake of e-cigarettes in the US population [20]. This survey assessed ever-use of e-cigarettes as well as reasons for use (for cessation, or for other purposes), and also use of pharmaceutical cessation aids. We compared the smoking characteristics between those who used ecigarettes for quitting and those who used pharmaceutical aids for quitting. We used multivariate regression to examine the associations of ever use of e-cigarettes and use of pharmaceutical aids for smoking cessation and to reduce cigarette consumption, particularly among heavier smokers.

\section{Methods}

\section{Data source}

The core CPS is a labor force survey conducted monthly by the US Census Bureau from a nationally representative civilian, non-institutionalized adult sample, in which households are interviewed for 4 consecutive months, rested for 8 months, and then re-interviewed for another 4 months before exiting the sample. For the TUS portion of the survey, an interview is attempted with all eligible adults in the household. If unsuccessful in obtaining the self-interview, a proxy interview is sought. The TUSCPS is funded by the U.S. National Cancer Institute and has been conducted since 1992 approximately every 3-4 years, to provide a nationally representative cohort of smokers and nonsmokers. The rotating panel design of the CPS provided an overlapped longitudinal sample of respondents to the May 2010 TUS survey (baseline) who were re-interviewed in May 2011 (follow-up; $n=28,153$ ). This longitudinal subsample of the TUS-CPS uses selfreport respondents only. Sample survey weights are provided to account for the complex sampling design, under coverage, and non-response in the overlap sample, allowing nationally representative estimates for the U.S. [21]. Data from the TUS-CPS contain no personal identifiers and are analyzed anonymously. The Institutional
Review Board at the University of California, San Diego reviewed the study protocol and did not consider it to be human subjects research.

\section{Cigarette smoking measures}

The TUS-CPS uses the standard national tobacco questions including "have you smoked at least 100 cigarettes in your entire life?" to identify ever smokers, and "do you now smoke cigarettes every day, some days, or not at all?" to identify current smokers. Average number of cigarettes smoked per day (CPD) was assessed. Change in consumption was computed as follow-up CPD minus baseline CPD, for continuing smokers. We classified those who smoked at least $15 \mathrm{CPD}$ as heavier smokers, as in previous work [22].

\section{Cessation behaviors at follow-up}

A quit attempt was identified with the question "during the past 12 months, have you stopped smoking for one day or longer because you were trying to quit smoking?" or "during the past 12 months, have you made a serious attempt to stop smoking because you were TRYING to quit - even if you stopped for less than a day?". Those who smoked fewer than 12 days in the past 30 days were alternatively asked "during the past 12 months have you tried to quit smoking completely?" Respondents who reported smoking at baseline but said they now smoked not at all at follow-up were asked "about how long has it been since you completely quit smoking cigarettes". We use $30+$ days cessation at the follow-up survey as an early marker of successful cessation [23-25]. As a sensitivity analysis, we used $30+$ days cessation on the longest quit attempt of the past 12 months [26, 27], which was assessed by "during the past 12 months, what is the longest length of time you stopped smoking because you were trying to quit". These quit attempts lasting at least 30 days were analyzed in the sensitivity analysis.

\section{Ever use of e-cigarettes}

At follow-up, ever-users of e-cigarettes were identified with the question "have you ever tried a product called an electronic or e-cigarette, such as 'Smoking Everywhere', 'NJOY', or other brands?" Use for quitting was assessed by the question "have you ever used e-cigarettes to help you quit smoking cigarettes or quit using other tobacco products?"

\section{Use of pharmaceutical assistance at most recent quit attempt}

At follow-up, those who had made a quit attempt were asked about use of the following products on the most recent attempt: "a nicotine patch, a nicotine gum or nicotine lozenge, a nicotine nasal spray or nicotine inhaler?; a prescription pill, called Chantix or Varenicline?; 
a prescription pill, called Zyban, Bupropion, or Wellbutrin? another prescription pill?".

\section{Other measures}

We classified respondents into age groups (18-24 years, 25-34 years, 35-49 years, 50 years and older), as male or female, as non-Hispanic White or other race/ethnicity, and into four levels of educational attainment (less than high school, high school, some college, college and above). Using the question, "how soon after you wake up do you typically smoke your first cigarette of the day?" those who smoked within 30 min of waking were considered more dependent. Age of initiation $<16$ years classified a respondent as an early initiator, assessed with the question "how old were you when you first started smoking cigarettes fairly regularly".

\section{Statistical methods}

We described the demographic and smoking characteristics among those who made any quit attempts, ever used e-cigarettes, and ever used e-cigarettes for quitting. Chi-squared tests were conducted to compare differences by e-cigarette use status. We also compared smoking characteristics by e-cigarette and pharmaceutical aid use status. We used multivariate logistic regression to examine the relationship of $30+$ day cessation at follow-up with ever use of e-cigarettes, and with use of pharmaceutical aids at last quit attempt, adjusted for baseline socio-demographic characteristics and nicotine dependence levels. E-cigarette use and use of pharmaceutical aids were coded as main effects in an additive model; these use categories are not mutually exclusive. Statistical significance was assessed at the two-sided $5 \%$ level. All statistics were computed using TUS-CPS overlap sampling weights according to recommended procedures [21], using SAS 9.3 (SAS Institute) survey procedures.

\section{Results}

In the longitudinal 2010-2011 TUS-CPS, there were 5255 baseline smokers who completed a self-reported interview. Follow- up information was available one year later on 3305 (62.9\%), however, only 2454 (46.7 \%) completed the follow-up interview themselves (rather than by proxy) and thus provided a detailed quitting history. These 2454 baseline current smokers comprised the current study sample.

\section{Characteristics of the baseline sample}

Table 1 summarizes the demographic and smoking characteristics of the cohort as well as quit attempts and e-cigarette use status. Of the baseline cigarette smokers $(N=2454), 43.6 \%$ made a quit attempt during the one-year follow-up period (Table 1) and this varied inversely with age $(52.1 \%$ to $40.0 \%$, youngest to oldest). Lighter smokers were more likely to have made a quit attempt than heavier smokers $(48.7 \%$ vs $37.3 \%$ ); those who smoked within $30 \mathrm{~min}$ of waking were less likely to make a quit attempt than those who did not (40.6\% vs $45.3 \%$ ).

\section{Ever use of e-cigarettes}

Of US smokers, an estimated $12.2 \%$ reported ever having used e-cigarettes in 2011 (Table 1). E-cigarette use was higher among younger age groups $(21.7 \%$ for those aged $18-24$ years vs $14.1 \%$ for ages $25-34$ years, and lower percentages in older age groups), and there was no gender difference. Ever-users were more likely to be non-Hispanic White than from other race-ethnic groups (13.8 \% vs $7.1 \%)$. Ever use increased with attained educational level, from $7.4 \%$ to $15.6 \%$. Heavier smokers were more likely to have used than lighter smokers (15.1\% vs $9.9 \%)$ and ever-users were more likely to have initiated before age 16 years than never-users (16.0\% vs $11.5 \%$ ).

Overall, $41.3 \%$ of those who had ever used ecigarettes said the reason for use was to help quit smoking. This percentage varied by age from a low of $31.0 \%$ for 18-24 years old users to almost half of ever-users who were over age 35 years. Non-Hispanic whites were more likely to have used e-cigarettes for quitting than were other race-ethnic groups (42.5\% vs $33.6 \%$ ), as were those with at least some college compared to those with lesser education. Lighter smokers were less likely than heavier smokers to have used for quitting. Those who initiated smoking under age 16 years were more likely to have used e-cigarettes for quitting than those who initiated later (58.9 \% vs $36.4 \%$ ). (Table 1 ).

\section{Pharmaceutical aid use on most recent quit attempt}

Of those with a quit attempt during the year, $20.1 \%$ reported using NRT and an additional $10.4 \%$ reported using Chantix. Only $3.1 \%$ reported using Zyban and $0.5 \%$ reported using any other pharmaceutical aid. Among smokers who used any pharmaceutical aid, $16.0 \%$ had quit for $30+$ days at follow-up, with little difference across type of pharmaceutical aid used. Accordingly, we used the combined category "any pharmaceutical use" on the most recent quit attempt for the remainder of this paper.

\section{Baseline smoking characteristics by product use}

Table 2 presents nicotine dependence characteristics by e-cigarette and pharmaceutical aid use status, among smokers with a quit attempt. As many smokers used multiple cessation aids, the e-cigarette and pharmaceutical aid use categories are not mutually exclusive. Smokers who either used a pharmaceutical aid on their 
Table 1 Past year quit attempts and ever use of e-cigarettes, by demographic characteristics, in a nationally representative cohort of U.S. smokers; TUS-CPS 2010-11 longitudinal sample

\begin{tabular}{|c|c|c|c|c|c|}
\hline & $N$ & (\%) & $\begin{array}{l}\text { Past- year quit } \\
\text { attempt (\%) }\end{array}$ & $\begin{array}{l}\text { Ever use of e-cigarettes } \\
\text { for any reason (\%) }\end{array}$ & $\begin{array}{l}\text { Ever use for } \\
\text { quitting (\%) }\end{array}$ \\
\hline Overall & 2454 & $(100 \%)$ & 43.6 & 12.2 & 5.0 \\
\hline \multicolumn{6}{|l|}{$\mathrm{Age}^{* * *}$} \\
\hline $18-24$ & 117 & (13.3\%) & 52.1 & 21.7 & 6.7 \\
\hline $25-34$ & 400 & (18.0 \%) & 45.5 & 14.1 & 4.8 \\
\hline $35-49$ & 818 & (30.3 \%) & 43.4 & 10.4 & 5.0 \\
\hline 50 and above & 1119 & (38.3 \%) & 40.0 & 9.4 & 4.6 \\
\hline \multicolumn{6}{|l|}{ Gender } \\
\hline Female & 1306 & (46.6 \%) & 47.6 & 12.0 & 5.6 \\
\hline Male & 1148 & (53.4 \%) & 40.2 & 12.4 & 4.6 \\
\hline \multicolumn{6}{|l|}{ Race/Ethnicity*** } \\
\hline Non-Hispanic White & 2001 & (76.2 \%) & 43.4 & 13.8 & 5.9 \\
\hline Other & 453 & (23.8 \%) & 44.3 & 7.1 & 2.4 \\
\hline \multicolumn{6}{|l|}{ Education** } \\
\hline Less than high school & 383 & $(17.6 \%)$ & 42.6 & 7.4 & 2.6 \\
\hline High school & 1005 & (40.1\%) & 42.5 & 12.0 & 4.7 \\
\hline Some college & 740 & (30.4 \%) & 47.0 & 13.9 & 6.4 \\
\hline College graduate & 326 & (11.9\%) & 40.5 & 15.6 & 6.4 \\
\hline \multicolumn{6}{|l|}{ Cigarettes/day $(\mathrm{cpd})^{* * *}$} \\
\hline$<15$ & 1244 & (53.5 \%) & 48.7 & 9.9 & 3.8 \\
\hline $15+$ & 1175 & (46.5 \%) & 37.3 & 15.1 & 6.6 \\
\hline \multicolumn{6}{|c|}{ Smoking < 30 min of waking } \\
\hline No & 1514 & $(64.4 \%)$ & 45.3 & 11.5 & 4.6 \\
\hline Yes & 890 & (35.6 \%) & 40.6 & 13.6 & 6.1 \\
\hline \multicolumn{6}{|l|}{ Smoking before age $16^{* * *}$} \\
\hline No & 2028 & (83.3 \%) & 43.5 & 11.5 & 4.2 \\
\hline Yes & 426 & (16.7 \%) & 44.2 & 16.0 & 9.4 \\
\hline
\end{tabular}

Note: $P$-values are from a chi-squared test across categories for differences in ever-use of e-cigarettes. Percentages are weighted to be representative of the U.S. population

${ }^{* *} p<0.01$, ${ }^{* * *} p<0.001$

last quit attempt or had ever used an e-cigarette to quit were more likely to be higher intensity smokers than those who did not (14.1 CPD, pharmaceutical aid users; 14.9 CPD, e-cigarette ever-users who used for quitting; $<12 \mathrm{CPD}$, other categories). They were more likely to smoke their first cigarette within the first $30 \mathrm{~min}$ after waking and more likely to have initiated smoking by age 15 years than those who did not use either e-cigarettes or pharmaceutical aids to quit.

Quit for 30+ days at follow-up, among those who tried to quit

Among smokers who tried to quit, $21.6 \%$ of those who had never used e-cigarettes were quit for $30+$ days at follow-up, similar to the $22.4 \%$ quit rate among those who did not use a pharmaceutical aid in their last quit attempt (Fig. 1). Ever use of an e-cigarette to quit was associated with a lower success rate $(11.1 \%$, Fig. 1) than those who had not used an e-cigarette, and this difference was significant in an adjusted logistic regression model (Table 3, $\mathrm{OR}_{\mathrm{adj}}=0.4,95 \%$ C.I.: 0.2-0.8). Similarly, smokers who used a pharmaceutical aid at last quit attempt had a lower success rate $(16.0 \%$, Fig. 1) than those who did not (Table 3, $\mathrm{OR}_{\mathrm{adj}}=0.7,95$ \% C.I.: 0.5-0.9). The success rate among those who ever used e-cigarettes for cessation was observed to be substantially lower than among those who used pharmaceutical aids at the last quit attempt (Fig. 1). In a sensitivity analysis, the same model using as outcome any cessation of 30+ days during the past year had consistent results (Table 4) and the cessation effect associated with use of e-cigarettes was significantly less than for use of pharmaceutical cessation aids. 
Table 2 Baseline smoking characteristics by product use, among those who made a quit attempt; TUS-CPS 2010-11 longitudinal sample

\begin{tabular}{|c|c|c|c|c|c|}
\hline & \multicolumn{3}{|l|}{ E-cigarette use status } & \multicolumn{2}{|c|}{ Pharmaceutical aid use status } \\
\hline & $\begin{array}{l}\text { Ever used e-cigarettes } \\
\text { for quitting }\end{array}$ & $\begin{array}{l}\text { Ever used e-cigarettes } \\
\text { for other purposes }\end{array}$ & $\begin{array}{l}\text { Never used } \\
\text { e-cigarettes }\end{array}$ & $\begin{array}{l}\text { Used pharma aids } \\
\text { at last quit attempt }\end{array}$ & $\begin{array}{l}\text { No use of pharma aids } \\
\text { at last quit attempt }\end{array}$ \\
\hline Sample size & 82 & 58 & 936 & 356 & 720 \\
\hline Cigarettes smoked/day (CPD) & 14.9 & 11.5 & 11.8 & 14.1 & 11.1 \\
\hline Time to $1^{\text {st }}$ cigarette $<30$ min from waking (\%) & 44.8 & 38.7 & 31.6 & 41.7 & 29.5 \\
\hline Duration of Cigarette Use (years) & 23.5 & 20.2 & 24.6 & 26.7 & 23.2 \\
\hline Smoking Before Age $16(\%)$ & 29.3 & 20.9 & 15.4 & 24.5 & 13.7 \\
\hline
\end{tabular}

Note: E-cigarette use status and pharmaceutical aid use status are not mutually exclusive. All data weighted to be representative of the U.S. population

\section{Change in cigarette smoking intensity over 12 months}

Figure 2 presents change in cigarette consumption for lighter and heavier smokers by categories of use of ecigarettes and pharmaceutical aids, separately for those who made a quit attempt and who did not. Among heavier smokers (15+ CPD) who did not make a quit attempt, all decreased their consumption over the year by 2.1 to $2.8 \mathrm{CPD}$, a regression-to-themean phenomenon. Heavier smokers who reported a quit attempt during the year decreased their consumption by 3.7-5.2 CPD and the largest decline was observed among those who reported no use of either e-cigarettes or pharmaceutical aids, although the difference between these groups was not significant. Among lighter smokers ( $<15 \mathrm{CPD})$ who did not make a quit attempt, cigarette smoking consumption increased over the year $(+2.5-4.3 \mathrm{CPD})$, again as expected from regression-to-the-mean. A similar pattern was seen among light smokers who made a quit attempt (+2.0-4.3 CPD), with the exception of those who ever-used e-cigarettes to quit. This group did not increase cigarette smoking consumption over the one-year follow-up period (change $=-0.6 \mathrm{CPD}, 95 \%$ $\mathrm{CI}=-1.9-0.7$ ), although again the difference between groups was not statistically significant. Multivariate linear regression adjusted for baseline characteristics provides consistent results (available upon request).

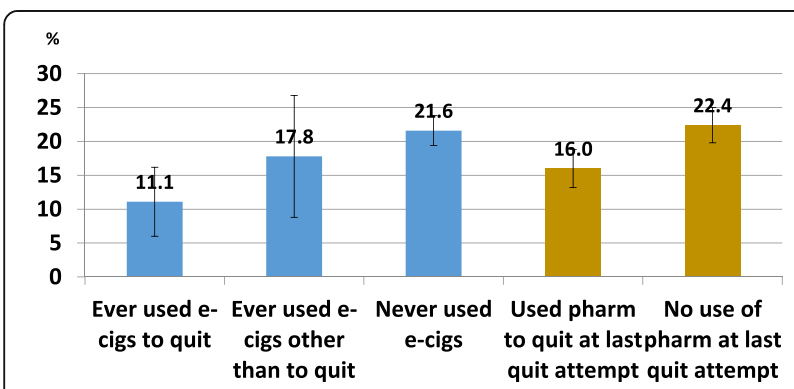

Fig. 1 Percentage of smokers with 30+ day cessation at follow-up, among those who made a quit attempt

\section{Discussion}

This is the first longitudinal study to use a nationally representative sample of U.S. smokers to provide evidence regarding the impact of e-cigarettes on smoking behavior at the U.S. population level. This study, conducted before e-cigarettes were widely used, did not find evidence that the ever-use of e-cigarettes as a cessation aid among these early adopters was associated with increased 30+ day smoking cessation at one-year followup. Further, reported ever use of e-cigarettes by heavier smokers was not associated with reduced cigarette consumption at follow-up. However, among lighter smokers, those who had ever used e-cigarettes for cessation had stable consumption levels, whereas all other light smokers showed increased consumption at follow-up, although these differences were not statistically significant.

In this study, those who had ever used e-cigarettes to quit or had used pharmaceutical aids on their most recent quit attempt equally appeared to be heavier, more dependent smokers. Such a finding is well known for pharmaceutical aids [28]. Thus, it was expected that success rates for e-cigarette users and for pharmaceutical aid users might be less than for non-users in this population study, as we found to be the case in both adjusted and unadjusted analysis. However, the data also suggest that cessation rates among those who had used e-cigarettes for quitting may be lower than cessation rates seen with use of a pharmaceutical aid.

While our study is the first which can provide nationally representative estimates for the U.S and focuses on early adopters who used first generation e-cigarettes, it supports results from the other published U.S. population-based longitudinal cohort study [19], as well as the summary results in meta-analysis across all 20 studies published as of this writing [8]. Most recently, a Canadian study of smokers enrolled in cessation assistance in the primary care setting showed association of e-cigarette use with poor cessation outcomes [29], consistent with our results. In contrast, relying on samples in two U.S. metropolitan areas Biener et al. [23] reported a strong association of smoking cessation with daily use of e-cigarettes for $30+$ 
Table 3 Logistic regression for 30+ day cessation at follow-up, among those who made a quit attempt; TUS-CPS 2010-11

\begin{tabular}{lcll}
\hline Variable & $\begin{array}{l}\text { Percent attaining } \\
\text { outcome }\end{array}$ & $\begin{array}{l}\text { Adjusted odds } \\
\text { ratio }\end{array}$ & $95 \% \mathrm{Cl}$ \\
\hline E-cigarette ever use status & & & \\
Never used & 34.9 & Reference & \\
Ever used to quit & 17.3 & 0.4 & $0.2-0.8^{* *}$ \\
Ever used other than & 30.4 & 0.7 & $0.4-1.5$
\end{tabular}

to quit

Pharmaceutical aid used for last quit attempt

\begin{tabular}{|c|c|c|c|}
\hline No & 34.7 & Reference & \\
\hline Yes & 29.5 & 0.7 & $0.5-0.9^{* *}$ \\
\hline \multicolumn{4}{|l|}{ Age } \\
\hline $18-24$ & 40.6 & Reference & \\
\hline $25-34$ & 38.8 & 1.5 & $0.9-2.6$ \\
\hline $35-49$ & 30.2 & 0.7 & $0.4-1.2$ \\
\hline $50+$ & 29.3 & 0.8 & $0.5-1.4$ \\
\hline \multicolumn{4}{|l|}{ Sex } \\
\hline Female & 33.9 & Reference & \\
\hline Male & 32.4 & 1.1 & $0.8-1.4$ \\
\hline \multicolumn{4}{|l|}{ Race/Ethnicity } \\
\hline Non-Hispanic White & 32.6 & Reference & \\
\hline Other & 35.0 & 1.0 & $0.7-1.3$ \\
\hline \multicolumn{4}{|l|}{ Education } \\
\hline Less than high school & 20.9 & Reference & \\
\hline High school & 32.1 & 2.2 & $1.4-3.4^{* * *}$ \\
\hline Some college & 40.5 & 4.0 & $2.6-6.1^{* * *}$ \\
\hline College gradate & 34.4 & 3.2 & $1.9-5.5^{* * *}$ \\
\hline \multicolumn{4}{|l|}{ Cigarettes smoked per day } \\
\hline$<15$ & 36.2 & Reference & \\
\hline $15+$ & 28.9 & 1.0 & $0.7-1.2$ \\
\hline \multicolumn{4}{|c|}{ Time to 1 st cigarette $<30$ min from waking } \\
\hline No & 34.2 & Reference & \\
\hline Yes & 31.5 & 0.9 & $0.7-1.2$ \\
\hline \multicolumn{4}{|c|}{ Smoking initiated before age 16 years } \\
\hline No & 32.3 & Reference & \\
\hline Yes & 37.4 & 1.2 & $0.8-1.7$ \\
\hline
\end{tabular}

${ }^{* *} p<0.01,{ }^{* * *} p<0.001$ All data is weighted to be representative of the U.S. population

days, as compared to non-users. However, most (66 \%) of those reporting daily e-cigarette use had adopted ecigarettes because they wanted to quit smoking, whereas non-users did not report the same motivation, and the resulting confounding by reverse causation can account for the reported association. Indeed, to control for such confounding in our study, we compared use and non-use of cessation aids only among those who had tried to quit, as in prior work $[26,27,30,31]$; without this careful
Table 4 Sensitivity analysis: logistic regression for any 30+ day cessation during the past year, reported at follow-up, among those who made a quit attempt; TUS-CPS 2010-11

\begin{tabular}{llll}
\hline Variable & $\begin{array}{l}\text { Percent attaining } \\
\text { outcome }\end{array}$ & $\begin{array}{l}\text { Adjusted odds } \\
\text { ratio }\end{array}$ & $95 \% \mathrm{Cl}$ \\
\hline E-cigarette ever use status & & Reference & \\
Never used & 21.6 & 0.3 & $0.2-0.5^{* * *}$ \\
Used to quit & 11.1 & 0.7 & $0.4-1.3$
\end{tabular}

Pharmaceutical aid used for last quit attempt

$\begin{array}{llll}\text { No } & 22.4 & \text { Reference } & \\ \text { Yes } & 16.0 & 0.8 & 0.6-1.1 \\ \text { Age } & & & \\ 18-24 & 22.6 & \text { Reference } & \\ 25-34 & 31.3 & 0.9 & 0.5-1.4 \\ 35-49 & 16.1 & 0.6 & 0.4-1.1 \\ 50+ & 17.5 & 0.6 & 0.4-1.0 \\ \text { Sex } & & & \\ \text { Female } & 20.0 & \text { Reference } & \\ \text { Male } & 21.1 & 1.0 & 0.8-1.2 \\ \text { Race/Ethnicity } & & & \\ \text { Non-Hispanic White } & 20.9 & \text { Reference } & \\ \text { Other } & 19.2 & 1.2 & 0.9-1.6\end{array}$

Education

$\begin{array}{llll}\text { Less than high school } & 9.1 & \text { Reference } & \\ \text { High school } & 17.6 & 2.0 & 1.4-2.7^{* * *} \\ \text { Some college } & 28.6 & 2.7 & 1.9-3.8^{* * *} \\ \text { College gradate } & 24.5 & 2.2 & 1.4-3.5^{* * *}\end{array}$

Cigarettes smoked per day

$\begin{array}{llll}<15 & 22.5 & \text { Reference } & \\ 15+ & 17.8 & 0.8 & 0.6-1.0^{*}\end{array}$

Time to 1 st cigarette $<30$ min from waking

$\begin{array}{llll}\text { No } & 22.2 & \text { Reference } & \\ \text { Yes } & 17.4 & 1.1 & 0.8-1.4\end{array}$

Smoking initiated before age 16 years

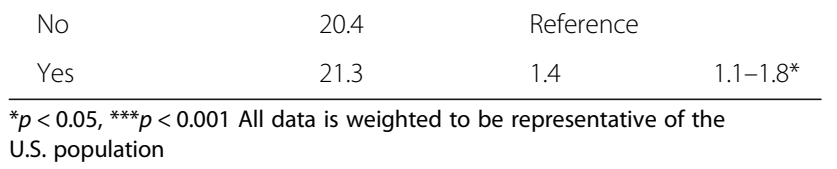

choice of comparison group, we are able to replicate a spurious association which is similar in magnitude to that reported by Biener et al. [23] (data available upon request). However, our study is unable to address whether extensive and heavy use of e-cigarettes might facilitate cessation, as we were unable to find such users in the national population. As e-cigarette use moves beyond early adopters into the population and product innovation continues, such heavy use may become more common allowing the 


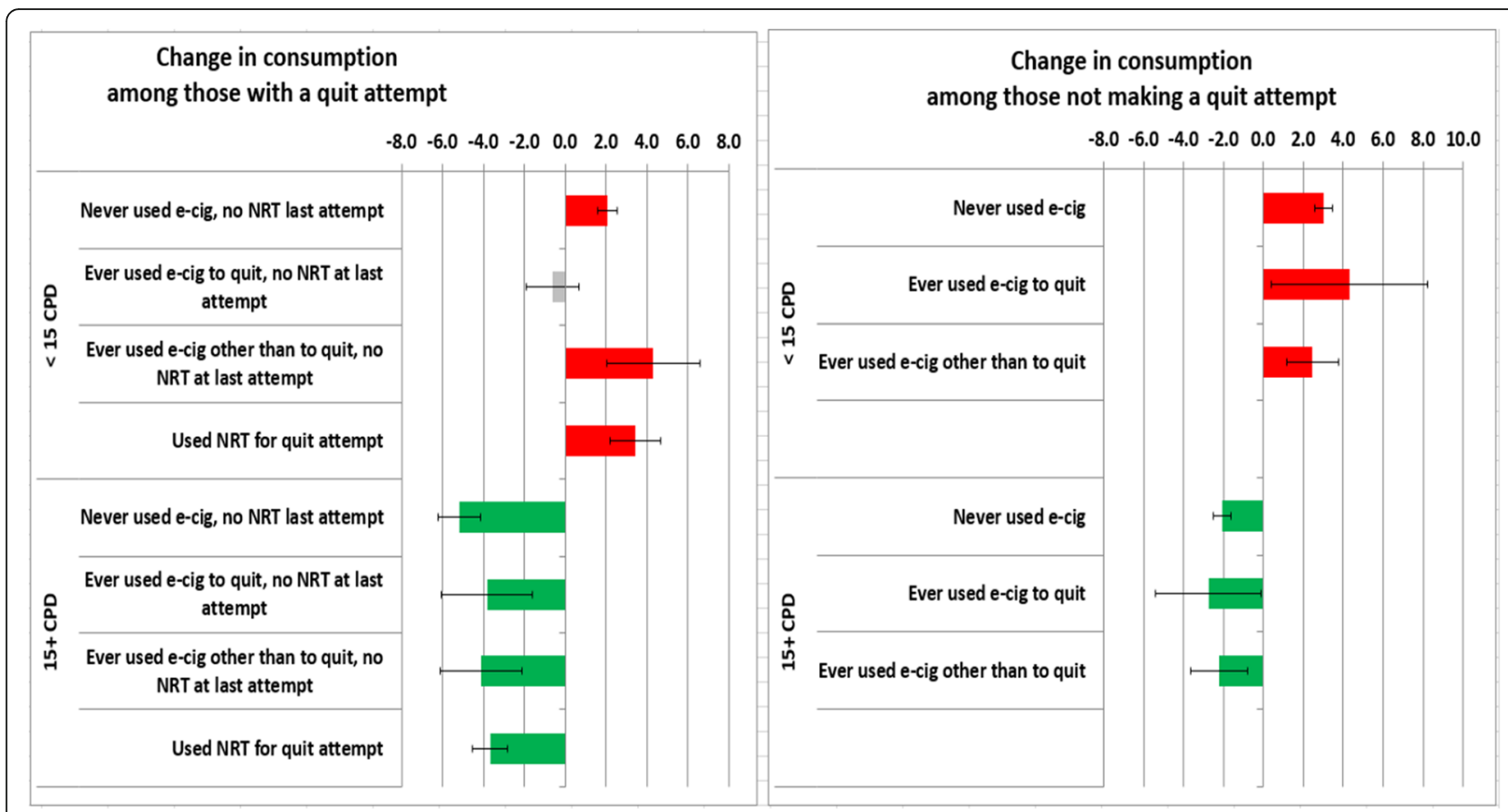

Fig. 2 Changes in smoking intensity among smokers by product, baseline consumption level and reported cessation attempts

association with cessation to be further tested [6,32]. Our observation that use of e-cigarettes by light smokers appeared to prevent increased consumption by follow-up was not hypothesized prior to this study. Thus, it is a hypothesis-generating observation in need of replication.

Our study has a number of limitations. The survey was conducted when e-cigarette use was uncommon but rapidly increasing in the US. Accordingly, the e-cigarette question at follow-up only sought information on everuse, as well as whether the use was for cessation. Ideally, the usage report would have been linked directly to the most recent quit attempt. However, in 2009 ever use of e-cigarettes among smokers was less than $2 \%$, and $40 \%$ of ever-users also reported past 30-day use [4, 33]. Thus we expect that most reported use fell within the past year, as did the quit attempt. However, these findings need to be replicated in other nationally representative longitudinal studies. Although the diversity of e-cigarette products was much smaller in 2010-2011 than at present [32], the TUS-CPS treated e-cigarettes as a single homogeneous product and there was no information on intensity of use, whereas others have noted substantial variability in nicotine levels, patterns of use and customer experiences [34-36]. In the future it will be important to investigate patterns of cigarette use among sub-populations of e-cigarette users.

\section{Conclusions}

Among early adopters of first generation products, ever-use of e-cigarettes to aid cigarette smoking cessation was not associated with either improved cessation outcomes or with reduced cigarette consumption, in the U.S. population. The data also suggested that cessation rates among those who had used e-cigarettes for quitting may be lower than cessation rates seen with use of a pharmaceutical aid in the U.S. Thus, this study suggests that it is premature to conclude that e-cigarettes will be helpful to smokers who make a quit attempt. It also seems premature to conclude that e-cigarettes will be an effective way for smokers, especially heavy smokers, to reduce the number of cigarettes that they smoke each day. Given the intensive marketing and rapid increase in use of e-cigarettes, it will be important to study advertising content as well as smokers' attitudes and beliefs regarding these products, in order to assess the role of e-cigarettes in changing smoking behavior.

\section{Funding}

This project has been funded with Federal funds from the National Institute on Drug Abuse at the National Institutes of Health, and the Food and Drug Administration, Department of Health and Human Services, (Contract No. HHSN271201100027C). Funding for the Tobacco Use Supplement (TUS) and its follow-up were sponsored by the National Cancer Institute at the National Institutes of Health and conducted by the Census Bureau in conjunction with the Bureau of Labor Statistics' and Census Bureau's Current Population Survey (CPS). In addition, Drs. Shi, Messer and Pierce were partially supported by the UC Tobacco-Related Disease Research Program (grant number 21RT-0135 to YS, KM and JPP), and the National Cancer Institute (grant number 1R01CA172058-02 to YS, KM and JPP). The role of Drs. Conway, Compton, and Ms. Hartman on this paper were through their involvement on Contract No. HHSN271201100027C. They had no involvement in the cited grants. 


\section{Availability of data and materials}

The datasets analyzed during the current study are available from the United States Census Bureau at: http://thedataweb.rm.census.gov/ftp/ cps_ftp.html\#cpssupps

\section{Authors' contributions}

$\mathrm{KM}, \mathrm{YS}, \mathrm{MV}$, and JP contributed to the study design and concept. Data acquisition was led by $\mathrm{AH}, \mathrm{MW}$ and $\mathrm{KM}$, and analysis and interpretation of the data was led by KM, YS, MW, JP, and WC. YS and KM provided statistical expertise in analyzing the data. YS, JP, and KM collectively contributed to the drafting of the manuscript, and all authors (WC, KC, SH, KM, JP, MV, MW, and YS) provided critical revision of the manuscript for important intellectual content. All authors read and approved the final manuscript. Lastly, KM and JP had full access to all of the data in the study and take responsibility for the integrity of the data and the accuracy of the data analysis.

\section{Competing interests}

We have read the journal's policy and the authors of this manuscript have the following competing interests: W.M. Compton reports minimal stock holdings (less than $\$ 10,000$ each) in the following companies with interest in healthcare research: $3 \mathrm{M}$ Company, General Electric Corporation, and Pfizer Inc. He has no other potential or actual conflicts to report. All other authors declare that there are no conflicts of interest. In addition, the views and opinions expressed in this presentation are those of the authors only and do not necessarily represent the views, official policy or position of the US Department of Health and Human Services or any of its affiliated institutions or agencies.

\section{Consent for publication}

Not applicable.

\section{Ethics approval and consent to participate}

Data from the TUS-CPS contain no personal identifiers and are analyzed anonymously. The Institutional Review Board at the University of California, San Diego reviewed the study protocol and did not consider it to be human subjects research.

\section{Author details}

${ }^{1}$ Cancer Prevention and Control Program, Moores UC San Diego Cancer Center, 3855 Health Sciences Drive \#0901, La Jolla, CA 92093-0901, USA. ${ }^{2}$ Department of Family Medicine and Public Health, University of California, San Diego, 9500 Gilman Drive \#0628, La Jolla, CA 92093-0628, USA. ${ }^{3}$ Division of General Internal Medicine/San Francisco General Hospital, University of California, San Francisco, 1545 Divisadero St, San Francisco, CA 94115, USA. ${ }^{4}$ National Institute on Drug Abuse, National Institutes of Health, 6001 Executive Boulevard, Bethesda, MD 20892-9589, USA. ${ }^{5}$ Tobacco Control Research Branch, Behavioral Research Program, Division of Cancer Control and Population Sciences, National Cancer Institute, National Institutes of Health, 9609 Medical Center Drive, Bethesda, MD 20892-9761, USA.

\section{Received: 21 January 2016 Accepted: 13 October 2016}

\section{Published online: 21 October 2016}

\section{References}

1. Benowitz NL, Goniewicz ML. The regulatory challenge of electronic cigarettes. JAMA. 2013;310(7):685-6.

2. Tan AS, Bigman CA. E-cigarette awareness and perceived harmfulness: prevalence and associations with smoking-cessation outcomes. Am J Prev Med. 2014:47(2):141-9.

3. Carroll Chapman SL, Wu LT. E-cigarette prevalence and correlates of use among adolescents versus adults: a review and comparison. J Psychiatr Res. 2014;54:43-54.

4. Regan AK, et al. Electronic nicotine delivery systems: adult use and awareness of the 'e-cigarette' in the USA. Tob Control. 2013;22(1):19-23.

5. King BA, et al. Trends in awareness and use of electronic cigarettes among US adults, 2010-2013. Nicotine Tob Res. 2015:17(2):219-27.

6. Rose SW, et al. The availability of electronic cigarettes in U.S. retail outlets, 2012: results of two national studies. Tob Control. 2014;23 Suppl 3:iii10-6.

7. Ro S. CHART OF THE DAY: E-cigarettes are selling like crazy. April 26, 2013, retrieved Oct, 2014; Available from: http://www.businessinsider.com/chart-ecigarette-growth-2013-4.
8. Kalkhoran S, Glantz SA. E-cigarettes and smoking cessation in real-world and clinical settings: a systematic review and meta-analysis. Lancet Respir Med. 2016;4(2):116-28.

9. Green SH, Bayer R, Fairchild AL. Evidence, policy, and E-cigarettes - Will England reframe the debate? N Engl J Med. 2016;374(14):1301-3.

10. Mckee M, Capewell S. Evidence about electronic cigarettes: a foundation built on rock or sand? BMJ. 2015;351:h4863.

11. Zhu S, et al. Interventions to increase smoking cessation at the population level: how much progress has been made in the last two decades? Tob Control. 2012;21(2):110-8.

12. Wagener TL, Siegel M, Borrelli B. Electronic cigarettes: achieving a balanced perspective. Addiction. 2012;107(9):1545-8.

13. Bhatnagar $A$, et al. Electronic cigarettes: a policy statement from the American Heart Association. Circulation. 2014;130(16):1418-36.

14. Leventhal $A M$, et al. Association of electronic cigarette use with initiation of combustible tobacco product smoking in early adolescence. JAMA. 2015; 314(7):700-7.

15. Primack BA, et al. Progression to traditional cigarette smoking after electronic cigarette use among us adolescents and young adults. JAMA Pediatr. 2015;169(11):1018-23.

16. Wills TA, et al. Longitudinal study of e-cigarette use and onset of cigarette smoking among high school students in Hawaii. Tob Control. 2016. doi:10. 1136/tobaccocontrol-2015-052705.

17. Kaisar MA, et al. A decade of e-cigarettes: limited research \& unresolved safety concerns. Toxicology. 2016;365:67-75.

18. Jensen RP, et al. Hidden formaldehyde in e-cigarette aerosols. N Engl J Med. 2015;372(4):392-4.

19. Grana RA, Popova L, Ling PM. A longitudinal analysis of electronic cigarette use and smoking cessation. JAMA Intern Med. 2014;174(5):812-3.

20. US Department of Commerce C.B. National Cancer Institute-sponsored Tobacco Use Supplement to the Current Population Survey (2010-11). Available at: http://appliedresearch.cancer.gov/tus-cps/. Technical documentation available at: http://www.census.gov/programs-surveys/cps/ technical-documentation/complete.html.

21. Davis WD, Hartman AM, Gibson JT. Weighting the overlap sample obtained from two tobacco use supplements to the current population survey. 2007. Available at: http://cancercontrol.cancer.gov/brp/tcrb/tus-cps/TUS-CPS_ overlap.pdf.

22. Messer K, et al. Smoking cessation rates in the United States: a comparison of young adult and older smokers. Am J Public Health. 2008:98(2):317-22.

23. Biener $L$, Hargraves $J$. A longitudinal study of electronic cigarette use among a population-based sample of adult smokers: association with smoking cessation and motivation to quit. Nicotine Tob Res. 2015;17(2): 127-33.

24. Cummins $S$, et al. Nicotine patches and quitline counseling to help hospitalized smokers stay quit: study protocol for a randomized controlled trial. Trials. 2012:13:128

25. Messer $\mathrm{K}$, et al. Cigarette smoking cessation attempts among current US smokers who also use smokeless tobacco. Addict Behav. 2015:51:113-9.

26. Messer K, Gamst A. The asymptotic distribution of the delete-d Jackknife variance estimator for smooth functionals. J Stat Plann Inference. 2008; 138(7):2154-62.

27. Messer $\mathrm{K}$, et al. The effect of smoke-free homes on smoking behavior in the U.S. Am J Prev Med. 2008;35(3):210-6.

28. Pierce JP, et al. Quitlines and nicotine replacement for smoking cessation: do we need to change policy? Annu Rev Public Health. 2012; 33:341-56.

29. Zawertailo $L$, et al. Concurrent e-cigarette use during tobacco dependence treatment in primary care settings: association with smoking cessation at 3- and 6-months. Nicotine Tob Res. 2016. doi:10.1093/ntr/ntw218.

30. Vijayaraghavan $\mathbf{M}$, et al. The effectiveness of cigarette price and smoke-free homes on low-income smokers in the United States. Am J Public Health. 2013;103(12):2276-83.

31. Messer K, et al. The California Tobacco Control Program's effect on adult smokers: (1) Smoking cessation. Tob Control. 2007;16(2):85-90.

32. Zhu S, et al. Four hundred and sixty brands of e-cigarettes adn counting: implications for product regulation. Tob Control. 2014;23 Suppl 3:iii3-9.

33. King BA, et al. Awareness and ever-use of electronic cigarettes among U.S. adults, 2010-2011. Nicotine Tob Res. 2013;15(9):1623-7. 
34. Etter JF, Bullen C. Saliva cotinine levels in users of electronic cigarettes. Eur Respir J. 2011;38(5):1219-20.

35. Goniewicz ML, Hajek P, McRobbie H. Nicotine content of electronic cigarettes, its release in vapour and its consistency across batches: regulatory implications. Addiction. 2014;109(3):500-7.

36. Goniewicz ML, et al. Nicotine levels in electronic cigarettes. Nicotine Tob Res. 2013;15(1):158-66.

Submit your next manuscript to BioMed Central and we will help you at every step:

- We accept pre-submission inquiries

- Our selector tool helps you to find the most relevant journal

- We provide round the clock customer support

- Convenient online submission

- Thorough peer review

- Inclusion in PubMed and all major indexing services

- Maximum visibility for your research

Submit your manuscript at www.biomedcentral.com/submit 